Fixed Point Theory, 20(2019), No. 1, 255-270

DOI: $10.24193 /$ fpt-ro.2019.1.17

http://www.math.ubbcluj.ro/ nodeacj/sfptcj.html

\title{
THE SET OF SOLUTIONS TO A NONLINEAR INTEGRODIFFERENTIAL EQUATION IN N VARIABLES
}

\author{
LE THI PHUONG NGOC*, HUYNH THI HOANG DUNG ${ }^{* * * * * *}$ AND NGUYEN THANH \\ $\mathrm{LONG}^{* * *}$ \\ *University of Khanh Hoa, 01 Nguyen Chanh Str., Nha Trang City, Vietnam \\ E-mail: ngoc1966@gmail.com \\ ** Department of Basic Sciences, University of Architecture Ho Chi Minh City, \\ 196 Pasteur Str., Dist. 3, Ho Chi Minh City, Vietnam \\ E-mail: dunghth1980@gmail.com \\ ***Department of Mathematics and Computer Science, University of Science \\ Vietnam National University Ho Chi Minh City, 227 Nguyen Van Cu Str., Dist. 5 \\ Ho Chi Minh City, Vietnam \\ E-mail: longnt2@gmail.com
}

\begin{abstract}
In this paper, we study the existence and the compactness of the set of solutions for a nonlinear integrodifferential equation in $\mathrm{N}$ variables. The main tools are the fixed point theorem of Krasnosel'skii with the definition of a suitable Banach space and a sufficient condition for relative compactness of subsets in this space. An illustrative example is given.

Key Words and Phrases: Nonlinear integrodifferential equation, the fixed point theorem of Krasnosel'skii.
\end{abstract}

2010 Mathematics Subject Classification: 45G10, 47H10, 47N20, 65J15.

Acknowledgments. The authors wish to express their sincere thanks to the referees for the valuable comments and important remarks. Their comments uncovered several weaknesses in the presentation of the paper and helped us to clarify it. This research is funded by Vietnam National University Ho Chi Minh City (VNU-HCM) under Grant no. B2017-18-04.

\section{REFERENCES}

[1] M.A. Abdou, W.G. El-Sayed, E.I. Deebs, A solution of a nonlinear integral equation, Applied Math. Computation, 160(2005), 1-14.

[2] M.A. Abdou, A.A. Badr,M. M. El-Kojok, On the solution of a mixed nonlinear integral equation, Applied Math. Computation, 217(12)(2011), 5466-5475.

[3] A. Aghajani, E. Pourhadi, M. Rivero, J. Trujillo, Application of Perov's fixed point theorem to Fredholm type integro-differential equations in two variables, Mathematica Slovaca, 66(2016), 1207-1216.

[4] C. Avramescu, Some remarks on a fixed point theorem of Krasnosel'skii, E.J. Qualitative Theory of Diff. Equ., 5(2003), 1-15. 
[5] C. Avramescu, C. Vladimirescu, An existence result of asymptotically stable solutions for an integral equation of mixed type, Electronic J. Qualitative Theory of Diff. Equat., 25(2005), 1-6.

[7] C. Corduneanu, Integral equations and applications, Cambridge University Press, New York, 1991.

[8] K. Deimling, Nonlinear Functional Analysis, Springer, New York, 1985.

[9] B.C. Dhage, S.K. Ntouyas, Existence results for nonlinear functional integral equations via a fixed point theorem of Krasnoselskii-Schaefer type, Nonlinear Studies, 9(2002), 307-317.

[6] M.M. El-Borai, M.A. Abdou, M.M. El-Kojok, On a discussion of nonlinear integral equation of type Volterra-Hammerstein, J. Korea Soc. Math. Educ., Ser. B, Pure Appl. Math., 15(2008), no. 1, 1-17.

[10] M. Lauran, Existence results for some nonlinear integral equations, Miskolc Mathematical Notes, 13(2012), no. 1, 67-74.

[11] L.T.P. Ngoc, N.T. Long, Applying a fixed point theorem of Krasnosel'skii type to the existence of asymptotically stable solutions for a Volterra-Hammerstein integral equation, Nonlinear Anal. TMA., 74(11)(2011), 3769-3774.

[12] L.T.P. Ngoc, N.T. Long, On a nonlinear Volterra-Hammerstein integral equation in two variables, Acta Mathematica Scientia, 33B(2013), no. 2, 484-494.

[13] L.T.P. Ngoc, N.T. Long, Existence of asymptotically stable solutions for a mixed functional nonlinear integral equation in $N$ variables, Mathematische Nachrichten, 288(2015), no. 5-6, 633-647.

[14] B.G. Pachpatte, On Fredholm type integrodifferential equation, Tamkang J. of Math., 39(2008), no. 1, 85-94.

[15] B.G. Pachpatte, On Fredholm type integral equation in two variables, Differential Equations \& Applications, 1(2009), no. 1, 27-39.

[16] B.G. Pachpatte, Volterra integral and integrodifferential equations in two variables, J. Inequal. Pure and Appl. Math., 10(2009), no. 4, Art. 108, 10 pp.

[17] I.K. Purnaras, A note on the existence of solutions to some nonlinear functional integral equations, Electronic J. Qualitative Theory of Diff. Equat., 17(2006), 1-24.

[18] E. Zeidler, Nonlinear Functional Analysis and its Applications, Springer-Verlag New York Berlin Heidelberg Tokyo, Part I, 1986.

Received: May 11, 2016; Accepted: September 1st, 2016. 